I read with interest, and a burgeoning sense of disquiet, Gordon \& Haider's article (Psychiatric Bulletin, June 2004, 28, 196-198) on the use of 'drug dogs' in psychiatry. My interest was captured both by their authoritative survey of the problems associated with substance misuse, and their fulsome history of the lives and times of the aforementioned canines. Indeed, the authors appeared more concerned with the mental state of the dogs, mentioning the proper provision of 'periods of relaxation' and warning of the dangers of 'the dogs themselves becoming addicted to narcotics', than of the patients involved.

How apposite, in an era of increasingly authoritarian and coercive mental health legislation and provision (Zigmond, 2004), that this solution be proposed. Rather than attempt to understand the patients motives for consuming illicit drugs while in hospital (might boredom, unpleasant surroundings and overworked and distant staff play a role?), the authors suggest subsuming notions of patient-centred care, empathy, therapeutic alliances and a humane ethos, into the need to control behaviour. Yes the comorbidity of severe mental illness and substance misuse is a major problem, but can this stand as a solution? Should we not be expending more energy on the causes rather than the symptoms of this problem?
ZIGMOND, T. (2004) A New Mental Health Act for England and Wales: grounds for compulsion. Advances in Psychiatric Treatment, 1, 243-246.

Tim Calton Clinical Research Fellow, Department of Developmental Psychiatry, Queen's Medical Centre, Nottingham NG7 2UH

\section{Mental health review tribunals: recent problems}

For the past 20 years, there has been a steady increase in the number of applications to the MHRT. There were 5000 applications in 1986, rising to 20000 in 2000 (Department of Health Statistical Bulletin, October 2000). Applications outnumber hearings by $2: 1$ because so many patients are taken off section after the request has been submitted. This generates a lot of work for office staff but is unavoidable. A decade ago, tribunal members received reports in advance of hearings (except in Section 2 cases) and with the help of a clerk, the hearing could begin on time. Subsequent hearings were therefore not endangered.

A consecutive sample of hearings (total 107) attended by the author in the South Region (Hinchley Wood) beginning January 2002 and lasting 20 months was studied and a number of shortcomings identified. In 81 hearings not involving Section 2 patients, tribunal members received reports by post beforehand in only a third of cases. This meant that the Mental Health Act 1983 administrator had to provide the reports for members when they arrived for the hearing. At 69 of the 107 hearings in the sample, there was no clerk present to assist the tribunal. The time required to read reports contributes to the delay which is made worse because, in the absence of the clerk, members have to undertake some additional tasks. Delays cause frustration for everyone but the most serious consequence is that a later hearing may be cancelled or postponed. Patients generally find the prospect of a tribunal quite stressful and when a hearing is abandoned at the last moment it is not surprising that the treatment team encounters extra difficulties. Cancellation also causes inconvenience for legal representatives, witnesses, tribunal members and Mental Health Act 1983 administrators. There were 10 occasions in the sample when a key person was not present and the hearing had to be adjourned and rearranged at a later date by the office.

A major reorganisation of the tribunal system is at present taking place but it appears that many hearings are being arranged at the last moment with inevitable problems for everyone involved.

Brian Crossley Medical Member, South Region, MHRT. E-mail: rbcrossley@hotmail.com 